\title{
Outreach Psychotherapy for Seniors and Psychotherapy in Retirement Homes in German-speaking Countries - An Overview
}

\author{
Rabaioli-Fischer Barbara ${ }^{1, *}$, Söder Jessica² \\ ${ }^{1}$ Practice Researcher, Psychotherapy Practice Barbara Rabaioli-Fischer, Munich, Germany \\ ${ }^{2}$ Department of Psychology and Educational Sciences, Faculty of Psychology, Ludwig-Maximilians-University of Munich, Munich, \\ Germany
}

Email address:

praxbarab@t-online.de (Rabaioli-Fischer B.), J.Soeder@campus.Imu.de (Söder J.)

${ }^{*}$ Corresponding author

\section{To cite this article:}

Rabaioli-Fischer Barbara, Söder Jessica. Outreach Psychotherapy for Seniors and Psychotherapy in Retirement Homes in German-speaking Countries - An Overview. American Journal of Psychiatry and Neuroscience. Vol. 9, No. 3, 2021, pp. 130-135.

doi: 10.11648/j.ajpn.20210903.20

Received: July 15, 2021; Accepted: August 27, 2021; Published: September 4, 2021

\begin{abstract}
Introduction: Growing older confronts seniors with a variety of challenges and problems. Dealing with losses or the transition to a retirement home and the abandonment of the previous life pose difficulties for people in old age. Although there is a great need for treatment, there are hardly any therapy offers in retirement homes or outreach psychotherapy for seniors. This article aims to provide an overview of the current state of studies on psychotherapy in retirement homes and outreach psychotherapy in German-speaking countries. Study Overview: For this purpose, 9 studies were examined in more detail. Different approaches to psychological and psychotherapeutic care of seniors were adopted in the described studies. In addition to specific therapy techniques, such as life review therapy, there were also non-specific counseling services, activations with music or a clinical consultation and lay service. Despite good approaches in the available studies, controlled research with sufficient samples for significant effects is lacking in this area. Also, the presented approaches often pose challenges to therapists and patients. Conclusion: In summary, this article aims to emphasize the importance of psychotherapeutic work with seniors, whether living at home or in a retirement home. The already elaborated and good approaches, such as life review procedures, should be further evaluated in controlled studies in the future. The studies presented here could provide inspiration for a study in a multicenter setting.
\end{abstract}

Keywords: Gerontological Psychology, Life Review Procedures, Outreach Psychotherapy, Psychotherapy in Retirement Homes

\section{Introduction}

The need for treatment of mental disorders in retirement homes has been documented in many publications over the last years. Laireiter et al. [8] draw attention to the increased prevalence of mental disorders in retirement and nursing homes. Seniors often know little about mental disorders and have little motivation to enter mental health treatment. But although seniors' readiness for treatment is lower than that of younger people, they have an increased need for treatment due to higher prevalences of disorders [19]. Studies on outreach psychotherapy in the home environment of senior citizens, however, are hardly available. This is even though it is known that seniors living at home also suffer from restrictions in mobility, social participation, or independent living. However, these problems are often not recognized, and psychotherapy is not arranged [21]. Despite research on the inpatient setting, there are still few to no therapy services for frail seniors living at home, even though there are certainly forms of therapy that can be done well with the elderly, such as Cognitive Behavioral Therapy, Problem Solving Therapy (PST), Life review therapy (LRT) [17, 18], or Interpersonal Therapy [21]. The lack of provision for seniors living at home could be explained by the complexity of the outreach psychotherapy setting. There is a massive gap between need and supply. 
In the inpatient setting, on the other hand, psychotherapy or psychological counseling is easier to integrate and evaluate. Many authors and their collaborators have been working for years on researching psychotherapeutic interventions or their specific requirements in retirement homes. This review is primarily concerned with work from German-speaking countries. The reason for this is that the conditions of care vary enormously internationally. First, however, the problems that can arise during the transition to a retirement home and the framework conditions that psychotherapy with seniors requires will be illuminated.

\subsection{Psychological Consequences of Moving to a Retirement or Nursing Home}

The transition to a retirement home is a challenge for seniors as well as for their relatives and caregivers. Particularly relevant here is the change of residence, which represents a critical life event [16]. Since the move to the home represents a dissolution of the previous life and probably the last move before death, this event is associated with threat, life change, loss (persons, possessions, or privacy), pain, farewell, and grief. All these aspects make the move to the retirement home critical and stressful [12]. The consequence of moving from a previously autonomous lifestyle to an assisted living facility can be manifold, for example, the feeling of being a burden to others, loss of motor skills, inability to eat a meal properly, loss of mobility, loss of autonomy, fear of the future, loss of perspective for further life planning, loss of social contacts, loneliness, lack of value and meaning, helplessness, anger towards one's own children, or a negative life balance [7].

Many patients experience that as a loss of dignity. The physical limitations require enormous mental energy. In such situations, many patients are challenged by others to find their "true self". This leads to an escape into new interests, such as religious communities or hobbies. In addition, thoughts arise, such as the thought of having given too much importance to one's profession in the past, or the thought of giving too much space to physical integrity and thus being inadequate. This sometimes agonizing, but in any case, necessary and involuntary adaptation to the new situation is glorified by many as "successful self-realization." This results in a considerable danger of trivialization.

Senior citizens experience the loss of autonomous living as particularly threatening and frightening. But the change of residence itself is also a stressor, as a study by Perrez et al. [16] showed. The stress is so great because it involves the dissolution of a beloved household, and the move is likely to be the last one before death. This is another reason why the change of residence is associated with evaluations that make life events critical [12]. Furthermore, the fear of loneliness or isolation is always present. This is quite justified if one considers the number of visits to nursing homes. $90 \%$ of all over 90-year-olds are single and $40 \%$ of nursing home residents do not receive any visitors. And especially with increasing length of stay and - included - worsening of the mental condition, the number of visits decreases rapidly. It is also possible that many of the senior citizens no longer have any relatives at all.

\subsection{Goals of Psychotherapeutic Work in Retirement Homes}

According to the Institute of the German Economy in Cologne, Germany could have a shortage of around 307,000 caregivers in inpatient care by 2035 . The supply gap in the care sector could increase to a total of almost 500,000 skilled workers by that year. The IW Cologne's forecast on the shortage of skilled workers is based on calculations by the Federal Statistical Office on the development of the need for care in Germany. The Covid-19 pandemic has made this shortage more than clear to all of us. It also made it even more understandable why seniors fear the transition to inpatient care and, if possible, want to avoid or delay it. If the move does take place, many demands follow to cope with this life event, such as readjustment, emotional processing, cognitive restructuring, self-concept and behavioral change, and the establishment of new social relationships [12].

Psychotherapeutic support in nursing homes and homes for the elderly could help with all these demands and problems. There are various indications for this type of psychotherapy. For example, adjustment problems and disorders related to moving into the home, social conspicuities (aggressiveness, social withdrawal/isolation, reduction of social activities), challenging or disruptive behavior in the care context, acute or latent suicidality, critical life event with high risk valence (e.g., loss of a family member), biographical stresses (traumas), or chronified dysfunctional attitudes and beliefs can be reasons for therapy $[4,5,9]$. Because of these multiple indications for therapy, psychotherapy in such settings also has different roles and goals. Examples would include adjustment to the home during transition from the previous living arrangement, promotion of independence, mobility, and personal responsibility, improvement of social skills, reduction of social isolation/promotion of social integration, coping with stress, accepting reconciliation with the life lived, dealing with the issue of loss, coping with chronic attitudes, dealing with aging and death, and accepting the finite nature of life. In this context, remission of a chronic mental illness is not always the goal; much more often, one must be satisfied with partial remissions and acceptance of residual symptomatology [1]. The following specific attempts to implement these concepts have already been made and documented.

\section{Study Overview}

\subsection{Project "Psychotherapy in Retirement Homes" [8, 9, 11])}

In an outreach approach, residents of senior citizens' homes in the city of Salzburg were provided with psychotherapeutic care. So far, a total of 201 persons (145 female, 76.6\%) have been treated, whereby dropouts were not considered. The therapies carried out in this project were based on the special 
gerontological principles mentioned above. The psychotherapy was carried out on an outreach basis and was usually carried out after the residents' abnormalities were identified by the nursing staff or doctors of the retirement home. The starting point was usually an externally indicated wish for therapy by the nursing staff, which required a special design of the therapy acceptance, an extended informed consent (with nursing staff and relatives) and a careful establishment of the therapeutic relationship. The diagnostic phase was followed by the goal clarification phase and the development of the treatment plan, involving caregivers and relatives as appropriate. The developed goals included not only the improvement of the psychological symptomatology, but also the adaptation to the home situation as well as individual goals such as coping with grief. The methodological approach included a high proportion of general psychological/psychotherapeutic methods, such as client-centered interviewing, empathy and relationship support, life review and biographical work, clarification work, methods to promote positive experience, relaxation methods, cognitive restructuring, activation and daily structuring, cognitive confrontation and, when specific disorders were present, age-adapted disorder-specific methods (e.g., for depression).

The therapies have been evaluated several times since the project's inception. In various retrospective studies between 1997 and 2007 on a total of 87 patients (of whom 20 were men $=22.9 \%$; age: $\mathrm{M}=83.0, \mathrm{SD}=7.1$; range $=63-95$ years $)$, a significant improvement in well-being, a reduction in anxiety, depressiveness, sleep and adjustment problems, both from the point of view of the patients and from the point of view of the nursing staff and therapists, was demonstrated. In addition, there was a reduction in hospitalizations, psychiatric consultations, and use of psychotropic drugs. These effects persisted after 17 months.

A therapy-accompanying prospective study from 2000 to 2008 on residents* who completed therapy and of whom complete data sets were available $(\mathrm{N}=30 ; 7$ men $=23.3 \%$; age: $\mathrm{MW}=80.1 ; \mathrm{SD}=7.1$, range $=61-91$ years $)$ was able to underline and complement these results. The effects of the previous study were equally demonstrated, as well as additional positive effects on physical impairment and psychotic symptoms, although these were also smaller. Cognitive impairment showed slight to moderate deterioration, but this could also be due to the aging process. In general, this was a very elaborate study, but it also had some criticisms. There were only very small samples, consisting mainly of depressed women. Therefore, the results are difficult to generalize to other groups and diagnoses. In addition, there was no control group, so the results could also be spontaneous remission. Furthermore, this was only a completer analysis and not an intent-to-treat analysis, which makes closer investigations of drop-out difficult.

\subsection{The Move to a Retirement Home [22]}

Thiele-Sauer et al. [22] conducted a three-part research project. The aim of the first step was to find out what expectations and fears senior citizens and their relatives had about moving into a retirement home. In the second step, the concrete experiences that were made with the relocation were collected. Finally, in the last step, a psychological intervention program for seniors who are directly in the process of relocation was evaluated over 7 weeks.

In the first study on the expectations and fears of the seniors and their relatives, a mixed picture emerged. They both had positive expectations regarding the senior citizens' home in terms of satisfaction with the home's staff, health care, security, being able to organize their lives independently, having contact with relatives and room furnishings. The seniors were rather skeptical about the contacts within the retirement home, the financial situation, and the influence on living together, while their relatives had partly positive expectations here. Compared to the situation before the move, the seniors expected few changes in the areas of health care and safety. They and their relatives feared deterioration in the areas of independence, contact with people outside the retirement home, room furnishings and finances. Overall, the expectations of the seniors and their relatives differed significantly in only two characteristics. Expectations regarding room furnishings were viewed more positively by the seniors. On the other hand, the senior citizens expected a greater deterioration than their relatives regarding the independence of living arrangements. Across all categories, the relatives tended to be more skeptical than the seniors.

In the second study, the experiences with the move to a retirement home were surveyed. Here, the experiences were predominantly positive, as the move tended to be associated with an improvement or few changes in living conditions. The senior citizens and their relatives were critical of the influence they had on life in the retirement home and of making contacts there. Financially, a deterioration was perceived compared to the previous situation. However, the largely positive findings could also be due to social desirability or the fact that only satisfied seniors were selected by the home management for the survey. Health care, independent living, safety and contact with relatives were rated significantly more negatively by the relatives than by the seniors.

In study three, 20 seniors were followed for 7 weeks with an intervention program. The prerequisites were sufficient health fitness and willingness to participate. The intervention program was a semi-structured module system and consisted of four independent but interrelated thematic blocks (Module 1: Preparation and relocation; Module 2: The first days in the senior citizens' home; Module 3: Senior citizens' home as a living space; Module 4: Review and handover). For each module, specific goals were defined and worked on until the goal was achieved. Module 1 took place before moving into the retirement home. Module 2 followed when the residents moved in, and modules 3 and 4 were based on the current topics and needs of the residents.

Affectivity in the last seven days before relocation showed a slightly negative balance. The survey of depression scores revealed clear emotional distress with slightly elevated depressed mood. After implementation of the intervention, there were no significant changes in terms of positive or negative affectivity. There was a trend toward reduction in 
depression scores, but this was also not significant. In the supplementary survey, many nursing home residents still stated that they felt lonely. Nevertheless, the majority would decide to move again. The extent of adaptation assessed by the nursing staff only reached the threshold value for social behavior. However, the residents themselves rated their social life worse.

In summary, the small sample size does not allow any conclusions regarding the success of that intervention program. Due to the lack of a control group, a spontaneous remission of the slightly improved depression scores cannot be excluded.

\subsection{A Psychological Intervention Program for the Transition to a Retirement Home [13, 14]}

Mitmansgruber et al. [13] also developed an intervention program to facilitate the transition to a residential and nursing home for the elderly (see also Mitmansgruber et al. [14]), which aims primarily to build well-being and positive affectivity. Reduction of stress and negative affect should be achieved by providing information and assistance with organizational issues of relocation or move-in, maximizing perceived controllability in decision-making, activating environmental resources for the residents' needs, activating the residents' own resources, and problem-solving during the first weeks of relocation.

Building well-being and positive affectivity can be promoted by linking one's own important areas to opportunities in the home, building enjoyable activities, establishing contacts with staff and fellow residents, and activating the person's social network.

The program requires the treating person to have a good knowledge of the senior and his or her environment. From this data, an individual case concept is determined, which is the basis of the intervention.

The intervention program includes 4 thematic blocks (modules), each consisting of 2 sessions of approximately one hour, for a total of eight sessions. During the first module, the relocation is prepared. In the first session, the initial interview takes place at home, and in the second session, the preparation for the move takes place. The second module takes place during the first days in the retirement home. In the third session the room is furnished and in the fourth session the retirement home as a service is discussed. The third module deals with the retirement home as a living space. The fifth session therefore deals with activities and contacts in the home and the sixth session with contacts and activities outside the home. In the last module, a balance sheet and handover take place. In the seventh session the balance is taken, and difficulties are discussed. In the last session a conclusion is made and possibly the handover to a caregiver in the retirement home.

\subsection{Activation with Music to Improve the Mental State of Seniors in a Nursing Home [2]}

The aim of the study was to test the acceptance and feasibility of an intervention approach "activation with music" in a nursing home. Effects regarding the promotion or stabilization of cognitive performance and independence in the activities of daily living were evaluated. The "activation with music" is understood as a multimodal activation and is based on the guidelines "Seniorentanz plus" [23]. A total of 12 one-hour group sessions were conducted in the nursing home. Physically, the seniors were activated by dancing in a sitting position. In six sessions, additional strength, dexterity, and coordination were practiced with the help of balloons, soft balls, soft cubes, and strength banding. In addition, cognitive skills (attention, concentration, coordination, processing speed) were trained in the group. For this purpose, own tasks were invented, but the memory training of Oswald [15] and the memory games of Stengel [20] were also used.

A total of 16 residents took part in the program. Not all of them were always present at all sessions. The values for the extent of independence, for the general cognitive status, the ability to concentrate and for the assessment of complaints did not change significantly over the two measurement points (pre, post) until the follow-up.

In summary, again, the small sample size does not allow conclusions to be drawn about whether a program has no effect or whether the sample was simply too small to reliably detect an effect.

\subsection{Life Review in Nursing Home Residents with Depression. Qualitative Study of Behavioral Therapists' Experiences as Part of a Pilot Project [6]}

The purpose of this study was to gain insight into practice experiences of psychotherapists who provided outreach cognitive-behavioral depression treatments with elements of life review interventions in outpatient and nursing home settings. This was done to generate knowledge to improve care practices. Behavioral observations and focus group interviews were analyzed for this purpose. Data analysis was based on grounded theory. In addition, discussions with experts in geriatric psychotherapy, sociology, and public health were included. It was shown that the self-stabilization of the patients as well as the normalization and defusing of the current life situation are central in the therapy, while finding meaning and balancing played a subordinate role.

The study showed that older patients need a modified form of behavioral therapy. This should be enriched with basic life review interventions (LRI) and individual biography work. The patients should learn through the therapy and with the help of the therapists to deal with their own biography. This provides the necessary relief for the patients. Building on this, more complex forms of LRI can be applied later.

Interestingly, it became clear during the study that both patients and psychotherapists felt emotionally overwhelmed when working with life review procedures. Therapists felt overwhelmed by the abundance of biographical material and the emotional activation of the patients [6]. This implies that it is much more important to work in a contained and structured manner when working with life review procedures and biography. Haight \& Haight [3] also reported similar findings. They called for a well-bounded, structured approach in their 
"structured life review" approach so as not to overwhelm either the patients or the therapists.

Although the results are interesting, they are not a substitute for controlled research, which is particularly needed in psychotherapy in the retirement home or in outreach psychotherapy for the elderly. The present study and others in this field cannot be generalized to other psychotherapists or nursing homes. However, this study could be an indication of a possible approach to how psychotherapy with seniors could be effectively and better implemented.

\subsection{Clinical-gerontopsychological Consultation and Liaison Service in Retirement Homes [10]}

Although there is obviously a great need for gerontological care, the employment of gerontological psychologists is often impossible from an economic point of view. In addition, the project "Psychotherapy in Senior Citizens' Homes" showed that many problems of senior citizens do not require comprehensive psychotherapeutic help. Often it is more a matter of clarification, diagnosis, psychological counseling, or mediation [10]. A possible alternative would therefore also be care by trained nursing staff. One solution here would be the concept of a consiliary liaison service [4], as introduced and evaluated by Laireiter et al. [10] in a retirement home in Salzburg.

Here, seniors are cared for either directly from the outside (consultation) or through close cooperation with the ward team (in liaison). Such tasks can be taken over by specialist departments and outpatient clinics that do not run beds themselves [4]. In the pilot project of Laireiter et al. [10], the university outpatient clinic for clinical psychology and psychotherapy took over this task. The tasks in this study included psychological diagnosis and indication, psychoeducation, psychological interventions, counseling, and coaching. These tasks were performed by psychologists. In addition, there was close cooperation and regular discussions with the nursing staff. The evaluation of the project showed that the most frequent activities of the psychologists were talking to the nursing staff about patients, supervising residents and talking to the ward teams. In the work with the ward teams, topics about the residents and psychological specialist topics were dealt with. The offer of case conferences, staff coaching, discussion rounds and resident and family consultations were hardly used. Cooperation between the psychologists and the nursing staff was excellent, but there was no cooperation with the general practitioners and home physicians. Cooperation with the specialists in psychiatry and geriatrics, on the other hand, worked well. Overall, the family and home physicians showed little to no interest in the project and psychology in general, which could explain the results. Overall, the psychologists and nursing staff perceived the support and counseling of the nursing staff as more effective than the short-term support of the patients. Thus, training and assisting nursing staff in supporting psychological activities and providing short-term care to seniors by an external agency could be economic ways to make the lives of seniors in nursing homes more comfortable.

In general, it is important to consider certain framework conditions of psychotherapy in nursing homes. Since nursing home residents are often restricted in their freedom of movement, treatment should be low-threshold and outreach-based [8]. Moreover, residents seldom request treatment, which is why it is often provided by doctors, nursing staff or relatives. It is also always important to clarify the mandate and goals with the involvement of the institution and, due to the high comorbidity in old age, other disciplines (medicine, occupational therapy, physiotherapy) must always be included. Therapy with seniors also requires age-specific therapy goals and topics. Group therapies are not used because of the private relationships between the residents [9].

\section{Conclusion \& Recommendations}

The necessity of psychotherapeutic support for residents in nursing homes needs no further proof. This is mainly due to the pioneering work of Baumann, Laireiter and colleagues with numerous studies on this topic. However, it became clear in their work and in that of other authors that this psychotherapeutic work requires considerably more effort. They already describe [6] very helpfully necessary modifications, problem areas, limitations and ethical issues to the work of gerontological psychology. For outreach psychotherapy of older patients still living at home, no further studies can be found except for the publication of the authors Tegeler et al. [21]. They prove both the necessity of outreach work and the lack of need-based care for these patients. There are also no relevant studies in the last three years that have conducted systematic studies of psychotherapy care for seniors in nursing homes or at home. In the future, more studies should be conducted on psychotherapeutic care for seniors at home or in nursing homes. These studies should have better methodological standards in contrast to those available so far. Accordingly, there should be a sufficiently large sample that represents the average of the group to be cared for. In addition, the interventions should be offered for a sufficiently long time and should also be evaluated over a longer period of time. That will only be possible in big multicentered studies. This is the only way to determine how seniors can receive adequate psychotherapeutic care in the nursing home and at home. As this review article shows, psychotherapeutic care for seniors is an important topic that has not yet been adequately addressed. Due to the increasingly aging population in Western countries, this exciting field of research will also become more and more relevant in practice.

\section{References}

[1] Baumann, U., \& Laireiter, AR. (2013). Clinical psychological intervention, especially psychotherapy - even in older age? In E. Hellgart, L. Welker (Eds.), Wisdom and science. Festschrift on the occasion of the 25th anniversary of the senior studies program at LMU (pp. 315-344). Utz, Munich. 
[2] Böhler, G., \& Jenull, B. (2008). Activation with music: An intervention for nursing home residents/ residents to maintain cognitive performance and independence. Journal of Gerontopsychology \& Psychiatry, 21 (4), 267-272. https://doi.org/10.1024/1011-6877.21.4.267.

[3] Haight, B. \& Haight, B. (2007). The handbook of structured life review. Baltimore, MD: Health Professions Press.

[4] Heufft G, Kruse A, Radebold H (2006) Textbook of gerontopsychosomatics and geriatric psychotherapy, 2nd ed. Reinhardt, Munich.

[5] Hirsch R. (2010) Psychotherapy of the elderly. VPP 42: 677-694.

[6] Kessler, E.-M. (2016). Life review in nursing home residents with depression: qualitative study of behavioral therapists' experiences in a pilot project. Journal of Gerontology and $\begin{array}{llll}\text { Geriatrics, } & 49 & (6), & 520-525 .\end{array}$ https://doi.org/10.1007/s00391-015-0960-6.

[7] Kuhlmann, A. (2011). At the limits of our way of life. Texts on bioethics and anthropology. Frankfurt/Main: Campus.

[8] Laireiter, A.-R., Baumann, U., \& Messer, R. (2015). Gerontopsychology in senior care facilities. In A. Maercker (Ed.), Psychotherapy of aging and clinical gerontopsychology (pp. 289-313). Springer Berlin Heidelberg. https://doi.org/10.1007/978-3-642-54723-2_13.

[9] Laireiter AR, Baumann U, Lenzenweger R, Messer R, Thiele-Sauer C, Mitmansgruber U, Crombach H (2006). Clinical-geronto-psychological intervention in nursing homes-psychological therapy and consiliar- liaison activity: concept and results. Psychology in Austria 3: 169-183.

[10] Laireiter, A.-R., Baumann, U., Messer, R., Thiele-Sauer, C., Mitmansgruber, U., \& Crombach, H. (2007). Clinical-geronto-psychological consultation and liaison service in nursing homes: a pilot project. Journal of Gerontopsychology \& Psychiatry, 20 (2-3), 151-161. https://doi.org/10.1024/1011-6877.20.23.151

[11] Laireiter AR, Baumann U, Messer R, Lenzenweger R, Krammer E, Crombach H (2008) Psychotherapy in retirement homes. Concept and evaluation. Z Gerontopsych Psychiat 21: 61-69.

[12] Lazarus RS, Folkman S (1984). Stress, appraisal, and coping. Springer, New York.
[13] Mitmansgruber, H., Baumann, U., Feichtinger, L., \& Thiele, C. (2002a). Psychological intervention program for transition to retirement home - Concept and pilot study. Journal of Gerontological Psychology \& Psychiatry, 15 (4), 185-204. https://doi.org/10.1024//1011-6877.15.4.185.

[14] Mitmansgruber, H. Baumann, U., Feichtinger, L., \& Thiele, C. (2002b). Psychological intervention for transition to a retirement home. Guide for nursing staff. Federal Ministry for Social Security and Generations, Vienna.

[15] Oswald, W. D., \& Hagen, B. (Eds.). (1998). Memory training: A program for senior citizens' groups (2nd, fully revised and supplemented ed.). Hogrefe, Publ. for Psychology.

[16] Perrez M, Laireiter AR, Baumann U (2011) Psychological factors: stress and coping. In: Perrez M, Baumann U (eds) Lehrbuch Klinische Psychologie, Psychotherapie, 4th ed. Huber, Bern, pp 272-304.

[17] Rabaioli-Fischer, B. (2008). Outpatient psychotherapy with elders (1st ed.). Pabst Science Publ.

[18] Rabaioli-Fischer, B. (2015). Biographical work and life review in psychotherapy: a practice manual (1st ed.). Hogrefe.

[19] Soeder, U. (2002). Disorder epidemiology: prevalence, treatment needs, and care of mental disorders. In A. Maercker (Ed.), Old-age psychotherapy and clinical gerontopsychology (pp. 59-72). Berlin: Springer-Verlag.

[20] Stengel, F. (1997). Cheerful memory games: Training for mental concentration (7th ed.). Stuttgart: Memo-Berlag Ladner.

[21] Tegeler, C., Beyer, A.-K., Hoppmann, F., Ludwig, V., \& Kessler, E. (2020). Current state of research on psychotherapy for home-living vulnerable older adults with depression. Zeitschrift Für Gerontologie Und Geriatrie, 53 (8), 721-727. https://doi.org/10.1007/s00391-020-01805-3.

[22] Thiele-Sauer, C., Feichtinger, L., \& Baumann, U. (2008). The move to a retirement home: and experiences of seniors and their relatives: a final synopsis. Journal of Gerontopsychology \& $\quad$ Psychiatry, $21 \quad$ (1), $49-59$ https://doi.org/10.1024/1011-6877.21.1.49.

[23] Association Senior Dance Austria. (2004). Didactic and methodological internal working material for the training as dance leader senior dance plus. Stainach: Verein Seniorentanz Österreich. Available at: https://www.seniorentanz.at [10.05.2021]. 